\title{
AGROINDUSTRIALISASI KOPI ARABIKA JAVA PREANGER DI DESA MARGAMULYA KECAMATAN PANGALENGAN KABUPATEN BANDUNG
}

\author{
Endah Djuwendah, Tuti Karyani, Agriani H Sadeli, Kuswarini Kusno
}

Staf pengajar prodi agribisnis fakultas pertanian unpad endah.djuwendah@unpad.ac.id

\begin{abstract}
ABSTRAK
Kopi merupakan salah satu komoditas perkebunan unggulan yang sudah lama dibudidayakan. Selain berperan dalam penyerapan tenga kerja, Kopi menjadi komoditas ekspor yang bernilai ekonomi tinggi. Kopi terbaik dari Jawa Barat dikenal dunia internasional sebagai Java Preanger kopi. Kecamatan Pangalengan Kabupaten bandung merupakan salah satu sentra produksi kopi Java preanger yang potensial karena selain terdapat perkebunan kopi di wilayah ini juga berkembang industri pengolahannya. Tujuan dari penelitian ini adalah untuk mengetahui dinamika perkembangan agroindustri Java Preager Coffee di Desa Margamulya Kecamatan Pangalengan Kabupaten Bandung. Penelitian ini dilakukan dengan menggunakan desain deskriptif kualitatif dan teknis penelitin studi kasus. Pegumpulan data menggunakan metode observasi, wawancara dan studi literatur. Hasil penelitian menunjukkan bahwa proses agroindustri Java preager coffee yang terdapat di Kecamatan Pangalengan Bandung sudah berjalan dengan baik. Ini terbukti dari adanya perubahan yang terjadi dalam : (1) pertumbuhan dari pelaku usahtani, pengolahan hasil pertanian, distribusi dan input pertanian, (2) perubahan kelembagaan dan keorganisasian dalam hubungannya dengan perusahaan melalui peningkatan koordinasi vertikal dan perubahan dalam komposisi produk, teknologi, perwilayahan dan struktur pasar serta (4) peningkatan nilai tambah.
\end{abstract}

Kata kunci : Agroindustrialisasi, kopi arabica, Java preanger

\begin{abstract}
Coffee is one of the leading plantation commodities that has long been cultivated. In addition to playing a role in the absorption of work, coffee is a high-value export commodity. The best coffee from West Java is known internationally as Java Preanger coffee. Pangalengan District, Bandung regency is one of the potential Java preanger coffee production centers because in addition to coffee plantations in the region, the processing industry is also developing. The purpose of this study was to determine the dynamics of the development of Java Preager Coffee agroindustry in Margamulya Village, Pangalengan District, Bandung Regency. This research was conducted using descriptive qualitative design and technical research case studies. Collect data using the method of observation, interviews and literature studies. The results showed that the Java preager coffee agroindustry process in Pangalengan District of Bandung had gone well. This is evident from the changes that occur in: (1) growth of business actors, agricultural product processing, agricultural distribution and input, (2) institutional and organizational changes in their relationship with companies through increased vertical coordination and changes in product composition, technology, territories and market structure and (4) increase in added value.
\end{abstract}

Keywords: Agroindustrialization, arabica coffee, Java preanger

\section{PENDAHULUAN}

Kopi (Coffea Spp L) merupakan salah satu komoditas utama dan unggulan perkebunan yang memiliki nilai ekonomis tinggi. Pada tahun 2015 luas perkebunan kopi Indonesia mencapai 1.230.001 Ha dengan produksi 639.412 ton. Perkebunan kopi Indonesia didominasi oleh perkebunan rakyat $(94,22 \%)$ dan melibatkan petani secara langsung sebanyak 1,9 juta KK. Volume ekspor kopi Indonesia tahun 2015 adalah 502.021 ton dengan nilai $1.197,735$ juta \$ US. 
(Direktorat Jenderal Perkebunan, 2016). Menurut data ICO pada tahun 2015, Indonesia menempati urutan ke-4 sebagai negara penghasil kopi dengan volume produksi 9.350 ton (Karyani, dkk, 2017). Namun di sisi lain struktur industri pengolahan kopi nasional belum seimbang hanya $20 \%$ dalam bentuk kopi olahan (kopi bubuk, kopi instan dan kopi mix) dan $80 \%$ dalam bentuk kopi biji kering. sebagian besar kopi diekspor dalam bentuk biji kering dan dari $20 \%$ kopi olahan hanya mampu diekspor sebesar 3-4\% (widowaty, 2013).

Menurut data Direktorat jenderal Pekebunan tahun 2016 Jawa Barat menempati urutan ke 11 terbesar produsen kopi nasional. Luas lahan tanaman kopi di Jawa Barat mencapai 32.538 Ha dan menghasilkan 16.645 ton kopi. Pemerintahan daerah Jawa Barat berupaya mengembangkan kopi khas Jawa barat dan berhasil mendapatkan indikasi geografis pada tahun 2013 dengan nama Java Preanger kopi. Java preager cofee merupakan kopi arabika spesialty yaitu jenis kopi terbaik yang mempunyai aroma dan tekstur yang bersifat khas. Prospek pasar kopi jenis ini sangat baik karena pangsa pasar lokal maupun internasional saat ini terbuka lebar terutama dengan bergesernya konsumen kopi biasa ke kopi spesialti.

Sejarah menunjukkan Priangan merupakan perkebunan kopi pertama di Indoensia yang didirikan pada masa penjajahan Belanda. Melalui sistem tanam paksa Belanda memperluas perkebunan kopi hingga ke seluruh Indonesia. Masyarakat Eropa saat itu sangat mengemari kopi yang berasal dari Jawa Barat dengan sebutan Java Preanger coffee bahkan memberikan istilah " $a$ cup of Java" karena kualitasnya tinggi dengan rasa dan aroman yang unik. Kejatuhan kopi Jawa Barat terjadi karena serangan penyakit karat daun yang mulai terjadi tahun 1878 . Setelah terjadinya serangan hama dominasi tanama kopi di jawa Barat tergantikan dengan tanaman teh. Kebangkitan kopi arabika java preanger di Pangalengan dimulai tahun 2001 setelah adanya kesepakatan para petani dengan perhutani terkait ijin penggunaan lahan hutan sebagai lahan pertanian yang sebelumnya ditanami sayuran diganti dengan tanaman keras seperti kopi, cengkeh, nangka dan lainnya untuk menjaga kelestarian hutan melalui program pengelolaan hutan bersama masyarakat (Lutfhi, 2017).

Kabupaten Bandung merupakan produsen kopi terbesar di Jawa Barat. Salah satu sentra kopi kabupaten Bandung berada di Kecamatan Pangalengan dengan volume produksi pada tahun 2016 mencapai 14.680 ton (BPS, 2017). Kopi di Pangalengan umumnya dijual petani dalam bentuk gelondongan basah (chery) kepada koperasi, badar dan usaha pengolahan kopi. Saat ini terdapat 5 pabrik pengolahan di Pangalengan berbentuk badan usaha koperasi, perseroan terbatas (PT) maupun perusahaan perseorangan. Pelaku agroindustri kopi tersebut melakukan pengolahan kopi java preanger menjadi green bean, roasted bean dan ground coffee yang sesuai dengan kebutuhan konsumen.

Agroindustri adalah kegiatan memanfaatkan hasil pertanian sebagai bahan baku, merancang dan menyediakan peralatan serta jasa untuk kegiatan tersebut dengan produk akhir yang siap dikonsumsi ataupun sebagai produk bahan baku industri lainnya (Mardiharini dan Erizal (2012). Menerut hasil penelitian Gea Xena Levina dan Lucyana Trimo (2014) sumberdaya kopi di Kecamatan pangalengan, khususnya di kelompoktani Margamulya, berpotensi untuk pengembangan agroindustri kopi Java Preanger.

Perkembangan pertanian kopi rakyat di Desa Margamulya pada tahun 1990-2015 yang diikuti dengan perubahan aspek pertanian dari sistem tradisional ke sistem agribisnis dinilai cukup baik sehingga menimbulkan perubahan kehidupan sosial ekonomi masyarakat khususnya petani. Perubahan sosial dilihat dari aspek perubahan demografi, kepemilikan lahan pergtanian dan pendidikan. Sedangkan perubahan ekonomi dilihat dari mata pencaharian, pengembnafna sistem pertanian dan pendapatan masyarakat (Widiana, dkk, 2015).

Keberadaan Agroindustri kopi di Desa Margamulya Kecamatan Pangelengan telah membawa perubahan ekonomi dan sosial bagi warga setempat dalam menampung hasil produksi kopi, meningkatkan nilai tambah dan sumber pendapatan ekonomi masyarakat sehingga memberikan iklim makro yang kondusif bagi pengembangan java preanger kopi. Berdasarkan uraian di atas maka manarik untuk diteliti mengenai agroindustiralisasi dan nilai tambah agroindustri kopi java preanger di 
Desa Margamulya Kecamatan Pangalengan Kabupaten Bandung.

\section{METODE PENELITIAN}

Penelitian dilakukan dengan menggunakan desain penelitian kualitatif. Penelitian kualitatif merupakan metode untuk mengeksplorasi dan memahami makna yang oleh sejumlah individu atau sekelompok orang dianggap berasal dari masalah sosial atau kemanusiaan. Proses penelitian kaulaitaif melibatkan upaya penting seperti pengajuan pertanyaan dan prosedur, mengumpulkan data yagn spesifik dari para partisipan, menanalisis data secara induktif mulai daria tema yang khusus ke tema yang umum dan menaksirkan makna data (Creswell, 2010). Teknis penelitian yang digunakan adalah studi kasus. Studi kasus merupakan metode yang digunakan untuk mempelajari secar intensif atau mendalam suatu anggota dari kelompok sasaran suatu obyek penelitian. Obyek yang dikaji dalam penelitian ini adalah agroindustrialisasi kopi arabika java preanger di Desa Margamulya Kecamatan Pangalengan kabupaten Bandung. Data primer diperoleh dari informan yang terdiri dari petani kopi, koperasi, perusahaan pengolah dan bandar kopi di Desa Margamulya. Data sekunder diperoleh melalui studi kepustakaan, penulusuran internet, BPS, Dinas pertanian/perkebunan, jurnal dan data dari instansi yang terkait dengan penelitian ini. Teknis analisis data dilakukan secara deskriptif melalui aktifitas pengumpulan data, reduksi data, penyajian data dalam bentuk tabel dan penarikan kesimpulan.

\section{HASIL DAN PEMBAHASAN}

Pertumbuhan Pelaku Agroi input dan Distribusi Java Preanger Coffee. Menurut Arifin dalam Mayasari (2016), agroindustrialisasi tidak hanya tengolahan hasil oleh sektor industri, melainkan mencakup proses peningkatan nilai tambah sampai pada koordinasi dan integrasi vertikal antara sektor hulu dan hilir. Sedangkan Wilkinson dalam Noor (2011) menyatakan agroindustrialisasi sebagai perubahan, perkembangan ataupun pertumbuhan yang terjadi pada pelaku agroindustri di suatu wilayah.

Asal nama Pangalengan sendiri menurut Pak Acep sekretaris Kecamatan Pangalengan berasal dari kata Pangalengan yang berarti proses pengemasan kopi ke dalam kaleng yang telah ada sejak jaman penjajahan Belanda. Saat itu Pangalengan merupakan salah satu pemasok kopi arabika yang berkualitas. Kejatuhan kopi priangan di Pulau Jawa termasuk di Pangelengan diawali tahun 1876 setelah terserang penyakit karat daun akibat jamur Hemileia Vastatrix (HV). Terbitnya Undang-undang Agraria yang membuat para pengusaha perkebunan swasta bisa membuka lahan perkebunan dengan sistem sewa kepada pemerintahan Belanda juga turut menyebabkan kejatuhan kopi arabika Java priangan (Lutfi, 2017).

Pada tahun 1896 Karel Albert Rudolf (KAR) Boscha mendirikanan perkebunan teh di wilayah Malabar sehingga terjadi peralihan komoditas kopi menjadi teh. Pada tahun 1930 dominasi perkebunan kopi di Pangalengan tergantikan oleh teh yang menjadi primadona perdangan saat itu. Pasca kemerdekaan RI lahan Perhutani dimanfaatkan oleh petani dengan tanaman hortikultura. Namun hal ini tenyata menimbulkan kerusakan lingkungan seperti longsor dan banjir. Beberapa orang petani pelopor diantaranya pak Daud Yusuf, Iyus Supriyatna, Enjang Suryana, dan Asep Supratman pada tahun 1997 berinisiatif mengembalikan fungsi dan kelestarian hutan dengan menanam kopi dan mulai melakukan pendekatan kepada masyarakat.

Bibit Kopi yang ditanam pada awalnya berupa kopi Arabusta Timtim dan Catimor Jaluk yang juga dikenal dengan kopi Ateng singkatan dari Aceh Tengah (Palupi, 2014). Kedua varietas terakhir tersebut benihnya berasal dari seorang pedagang kopi asal Jawa Barat yang pernah tinggal di Aceh, bernama pak Nana. Pada saat terjadi konflik politik di Aceh sekitar tahun 1998-an, pak Nana kembali ke Jawa Barat dan mengembangkan kedua varietas tersebut.

Sejak tahun 2001-2002 petani pelopor menanam kopi di lahan Perhutani dan terus mengajak petani lainnya untuk menanam kopi. Panen perdana kopi arabika terjadi tahun 2003 dan saat panen raya tahun 2004 produktifitasnya mencapai $2-2,5$ ton/Ha/musim. Sejak itu masyarakat Pangalengan melihat tanaman kopi arabika prosfektif untuk diusahakan sehingga semakin banyak petani yang menanamnya. Pada saat itu Gubernur Jawa Barat juga mengeluarkan Keputusan No 522/224/binprod/ 20 Mei 2003 
yang melarang tanaman sayuran dan tumpangsari di tanam pada lahan dengan kemiringan $40 \%$ (Lutfi, 2017).

Pada tahun 2011 para tokoh kopi Jawa Barat membuat organisasi masyarakat yang bernama Masyarakat Perlindungan Indikasi Geografi Kopi Arabika Java Preanger (MPIG KAJP) yang bertujuan untuk melestarikan kopi arabika java Preanger. Sejalan dengan kebijakan tersebut Pemda Propinsi Jawa Barat melakukan bantuan pendampingan dan pembinaan pada petani, kelompoktani dan Koperasi produsen kopi. Pada tahun 2012 koperasi usaha bersama Kubangsari desa Pulosari dan kelompoktani Margamulya mendapatkan bantuan pendirian bangunan pabrik dan mesin pengolahan kopi. Pada tahun 2013 MPIG KAJP berhasil memperoleh sertifikasi indikasi geografis dan sejak saat ini pemerintah mengembangkan varietas baru berupa Lini S-759 dan Sigarar utang (varietas kopi arabika yang berasal dari sumatera utara).

Prestasi yang diraih dari pengembangan kopi java peanger terjadi mulai tahun 2011 kopi gunung tilu dari kelompoktani Margamulya mendapat juara ketiga citarasa kopi terbaik dari Puslitkoka Jember. Tahun 2012 Kopi Malabar dari kelompoktani Rahayu berhasil mendapat predikat kedua kopi terbaik setelah kopi Flores dari Puslitkoka Jember. Tahun 2015 kopi Gunung Tilu menjadi

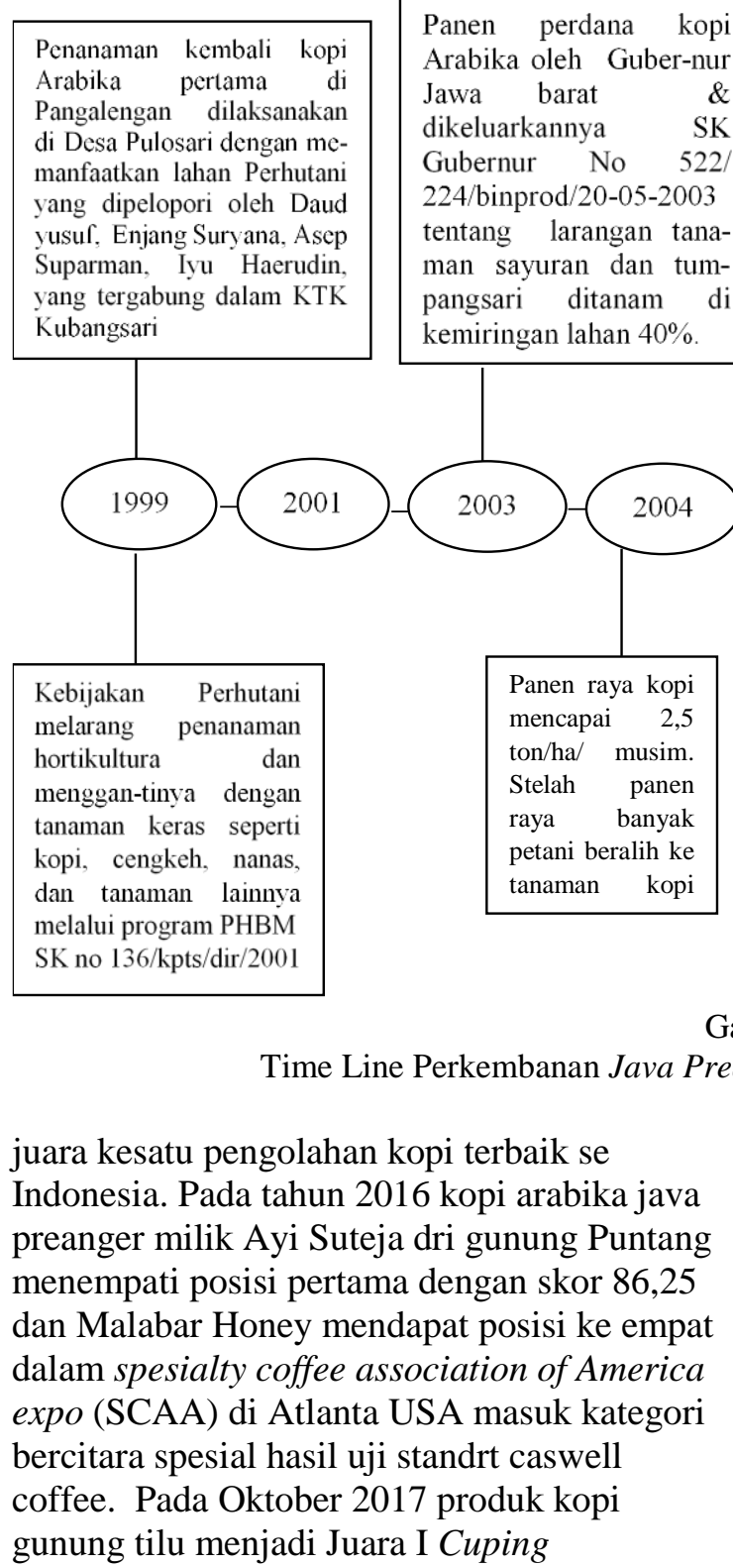

Gambar 1 banyak LMDH dan kelompok tani hutan diantaranya KTH Margamulya, Kubangsari dan Rahayu
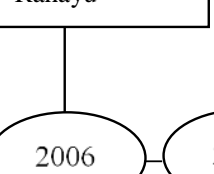

juara kesatu pengolahan kopi terbaik se Indonesia. Pada tahun 2016 kopi arabika java preanger milik Ayi Suteja dri gunung Puntang menempati posisi pertama dengan skor 86,25 dan Malabar Honey mendapat posisi ke empat dalam spesialty coffee association of America expo (SCAA) di Atlanta USA masuk kategori bercitara spesial hasil uji standrt caswell gunung tilu menjadi Juara I Cuping

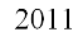

Terbentuk masyarakat perlindungan Indikasi Geografis Kopi java preanger (MPIG KAJP) arabika

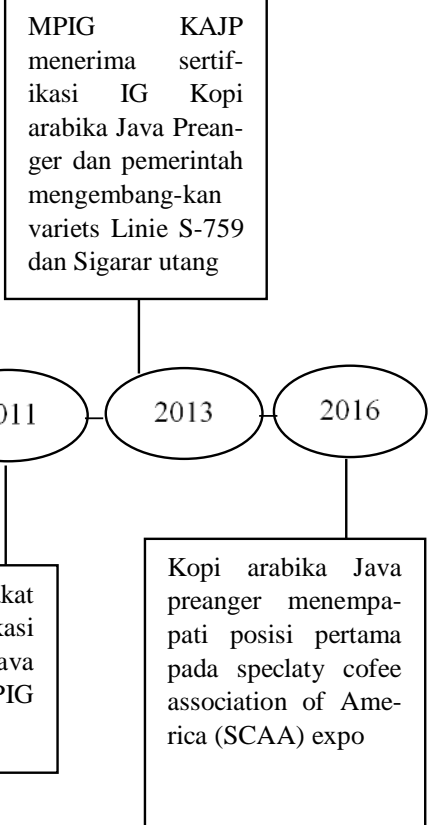

Competition Arabika Coffee Smesco Rembug Kopi Nusantara di Jakarta.

\section{Koordinasi Vertikal dan Struktur} Pemasaran Java Peanger Coffee. Terdapat keterpaduan dalam aktivitas on farm dan of farm melalui tahapan produksi, mengolah dan memasarkan java preanger coffee dalam suatu kesatuan yang saling berkaitan atau sering disebut sebagai koordinasi vertikal.

Keterpaduan komponen bahan baku di bagian hulu berupa penyediaan lahan dari Perhutani 
serta bantuan bibit kopi berkualitas dari Gubernur Jawa Barat yang disalurkan melalui Kelompoktani Rahayu dan Koperasi Produsen Kopi Margamulya. Di Desa Margamulya berdiri kebun induk kopi arabika varietas Sigagar Utang seluas 2 Ha yang dikelola oleh masyarakat desa Hutan Rahayu tani dan ditetapkan berdasarkan SK Menteri Pertanian No 65/Kpts/SR.120/2/2014. Bibit tanaman kopi itu dibagikan secara gratis kepada para petani melalui kelompok tani. Bantuan pupuk dan alat pengedali hama juga pernah diberikan kepada Kelompok tani Margamulya, kelompoktani Kubangsari dan Kelom poktani Rahayu.

Input tenaga kerja yang digunakan dalam aktifitas budidaya dan panen adalah petani lokal yang berasal dari masyarakat desa Margamulya. Koordinasi dalam pengingkatan keterampilan petani dilakukan dengan melibatkan Kelompok tani, Pusat Pelatihan Pertanian dan Pedesaan Swadaya (P4S) Rahayu Tani, Dinas Perkebunan Propinsi Jawa Barat dan Kabupaten Bandung. Pelaku agroindustri dan distributor

kopi di Desa Margamulya diantaranya Koptan Kowamah (2004), PT Nuga Ramitra milik Supritna Dinuri (2010), CV Prinsa Agrolestari milik Pak Wildan Mustafa (2012), PT. Sinar Mayang Lestari dmilik Slamet Prayoga (2012) dan Koperasi Produsen Kopi Margamulya (2014). Kemitraan dalam memasarkan produk dilakukan dengan berbagai perusahaan mitra diantaranya PT Taman Delta Indonesia (Semarang), PT Indocom Citra Persada(Surabaya), PT Karisma (Banten) dan PT Morning Glory (Bandung) yang merupakan distributor dan eksportir kopi di pasar dalam dan luar negeri .

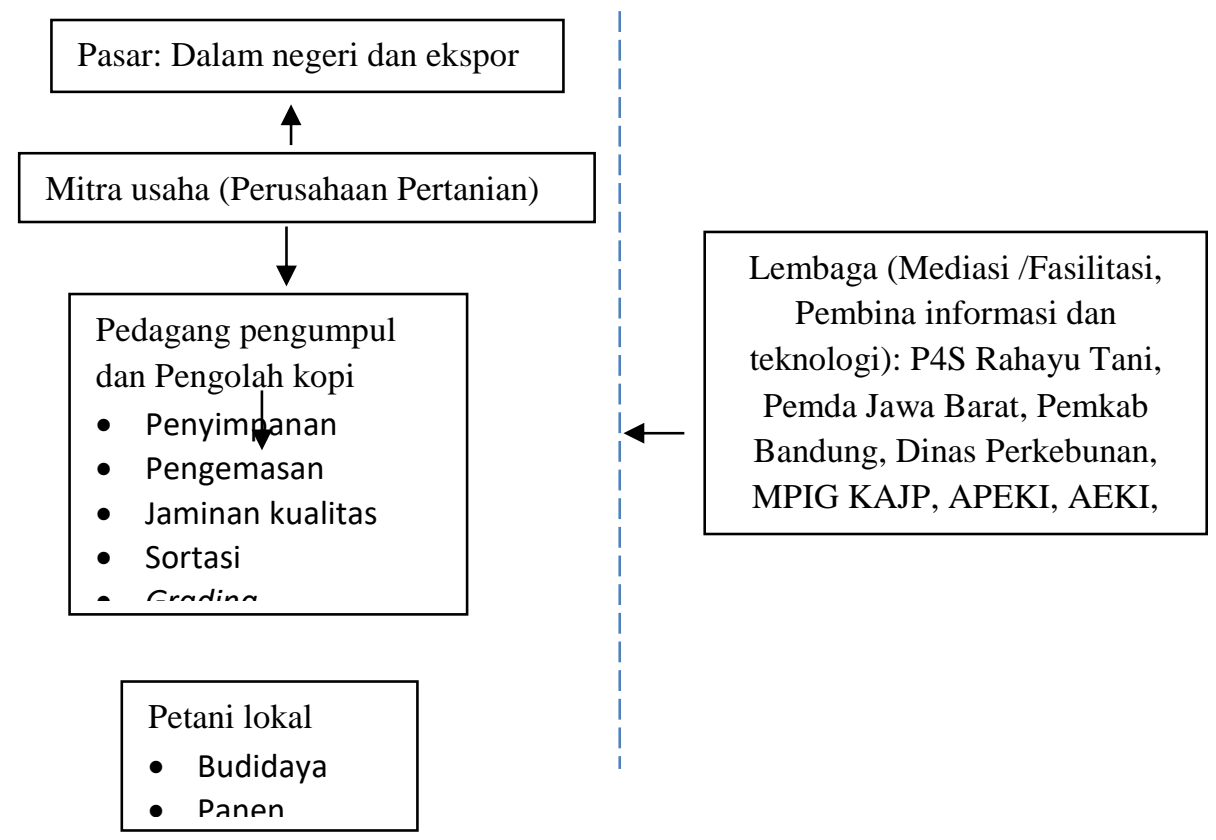

Gambar 2.

Alur Koordinasi Vertikal Java Preanger Coffee di Desa Margamulya Pangalengan Sumber : Luthfi, 2017 


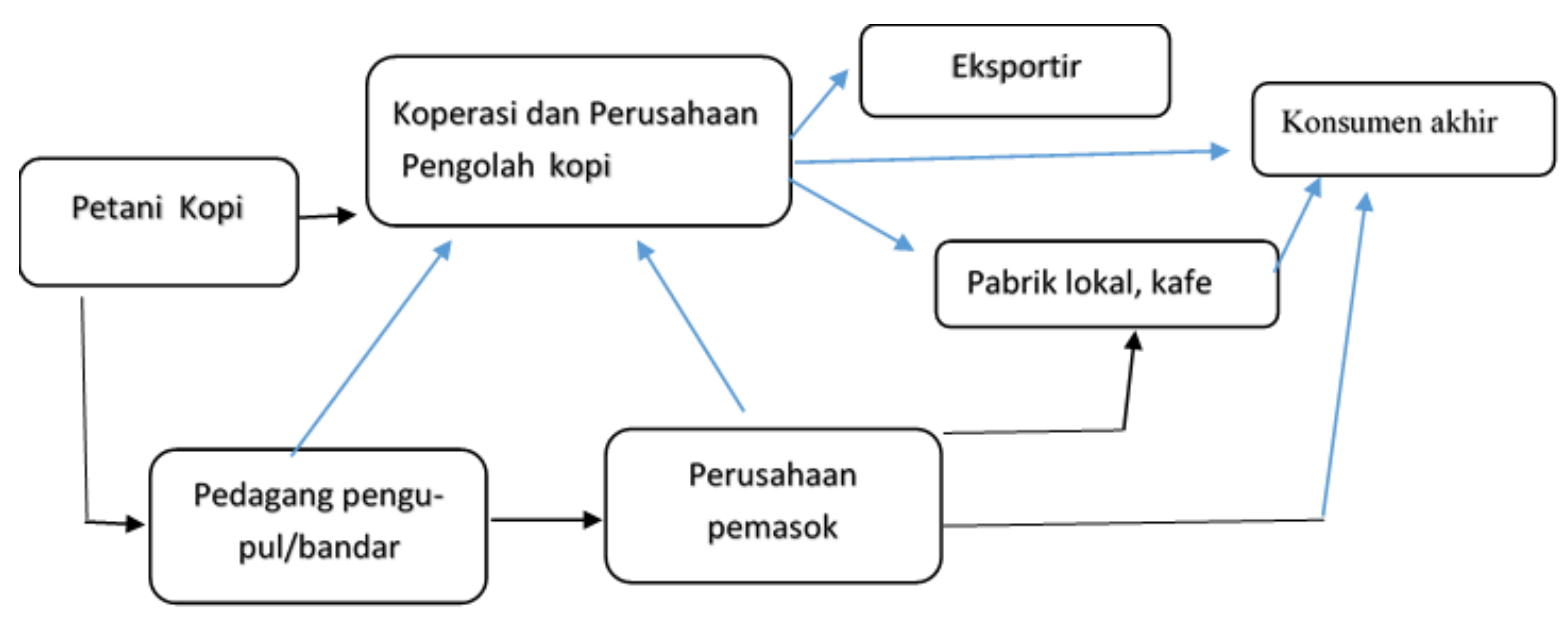

Gambar 3.

Rantai Pemasaran Java Prenger Coffee di Kecamatan Pangalengan

Terdapat beberapa organisasi yang terlibat dalam agroindustrialisasi kopi java preanger mulai dari budidaya kopi yaitu kelompoktani, Perum Perhutani dan APEKI (Asosiasi Petani Kopi Indonesia) yang bertugas mengajukan dana aspirasi ke anggota dewan dan dinas terkait, seperti dinas perkebunan, pertanian dan menentukan pasar untuk hasil panen kopi, AEKI (asosiasi eksportir kopi Indonesia) dan masyarakat perlindungan indikasi geografis kopi Arabika Java Preanger(MPIG-JKAP) yang bertujuan untuk melestarikan kopi arabika java preanger di Jawa Barat.

Pasar yang dituju oleh kopi arabika java preanger di Desa Margamulya adalah pasar dalam negeri dan pasar luar negeri. Pasar dalam negeri terdiri dari industri pengolahan kopi, kafe/kedai kopi yang tersebar di berbagai kota besar di Jawa Barat, Semarang dan Surabaya, konsumen yang membeli langsung dan pemasaraan on line. Sedangkan pasar luar negeri di ekspor ke berbagai negara diantaranya Korea selatan,
Maroko, Australia, Jerman dan Jepang melalui ekportir PT Taman Delta Indonesia, PT Sinar Mayang Lestari, Pt Kharisma dan Pt Sari makmur Mandiri (Medan).

Perubahan Teknologi, Komposisi Produk dan Perwilayahan. Panen raya kopi di Desa Margamulya berlangsung pada bulan Mei sampai Oktober. Ketersediaan bahan baku kopi dan industri pengolahan kopi menyebabkan desa Margamulya menghasilkan beragam produk olahan kopi seperti green bean, roasted bean dan ground coffee baik berupa kopi arabika reguler, Specialty Arabica Coffee dan Luwak Arabica Coffee. Produk agroindustri java preanger cofee yang dihasilkan dari Desa Margamulya Pangalengan memiliki beragam merek dagang diantaranya KAJP Gunung Tilu dari KMKP, kopi Malabar arabika dan kopi luwak Malabar dari PT. Nugra Ramitra yang bermitra dengan Kelompok Tani Rahayu, Malabar Mountain Coffee dan Golden Malabar dari PT. Sinar Mayang Lestari.

Tabel 1.

Perkembangan Teknologi dan Komposisi Produk Java Preanger Coffee

\begin{tabular}{|c|c|c|c|c|}
\hline \multirow[t]{2}{*}{ No } & \multirow[t]{2}{*}{ Keterangan } & \multicolumn{3}{|l|}{ Tahun } \\
\hline & & 2003 & 2010 & 2016 \\
\hline \multirow[t]{4}{*}{1.} & \multicolumn{4}{|c|}{ Teknologi yang digunakan dalam usahatani (on farm) } \\
\hline & a. Teknis pembibitan & $\mid \begin{array}{l}\text { Stek, } \\
\text { penyambungan }\end{array}$ & Stek, penyambungan & $\begin{array}{l}\text { Stek, } \\
\text { penyambungan }\end{array}$ \\
\hline & b. Varietas bibit & $\begin{array}{l}\text { Ateng, timtim, } \\
\text { kartika I }\end{array}$ & $\begin{array}{l}\text { Aterng, timtim, } \\
\text { Kartika, Linie S-795 }\end{array}$ & $\begin{array}{l}\text { Ateng, Timtim, kartika, Linie } \\
\text { S-759, sigarar utang }\end{array}$ \\
\hline & c. Pengolahan lahan & Traktor & Traktor & Traktor \\
\hline
\end{tabular}




\begin{tabular}{|c|c|c|c|c|}
\hline & d. Perawatan tanaman & $\begin{array}{l}\text { Pemupukan, } \\
\text { pemangkasan, } \\
\text { peremajaan }\end{array}$ & $\begin{array}{l}\text { peremajaan } \\
\text { Pemupukan, } \\
\text { pemangkasan, }\end{array}$ & $\begin{array}{l}\text { peremajaan Pemupukan, } \\
\text { pemangkasan }\end{array}$ \\
\hline & e. Pengairan & Selang, pompa air & $\begin{array}{l}\text { Selang, pompa air, } \\
\text { sprinkle }\end{array}$ & Selang, pompa air, sprinkle \\
\hline 2. & \multicolumn{4}{|c|}{ Teknologi yang digunakan dalam off farm } \\
\hline & a. Pemanenan & Abresan & Petik merah & Petik merah \\
\hline & b. Penimbangan & Timbangan manual & $\begin{array}{l}\text { Timbangan man-ual } \\
\text { dan digital }\end{array}$ & $\begin{array}{l}\text { Timbangan manu-al dan } \\
\text { digital }\end{array}$ \\
\hline & c. Pelepasan kulit buah & Pulper & Pulper, pulper-washer & $\begin{array}{ll}\mathrm{r} & \text { Pulper, pulper-washer } \\
\end{array}$ \\
\hline & d. Pelepasan kulit tanduk & Manual & Huller & Huller \\
\hline & e. Pembakaran (roasting) & $\begin{array}{l}\text { Mesin roasting } \\
\text { manual }\end{array}$ & $\begin{array}{l}\text { Mesin roasting } \\
\text { otomatis }\end{array}$ & Mesin roasting otomatis \\
\hline & f. Pengemasan & Karung, plastik & $\begin{array}{l}\text { Karung, plastik, } \\
\text { kertas, Alumunium } \\
\text { poil }\end{array}$ & $\begin{array}{l}\text { Karung, plastik } \\
\text { Kertas Kraft ber-lapis } \\
\text { aluminium foil (Zip lock) }\end{array}$ \\
\hline 3 & \multicolumn{4}{|l|}{ Perkembangan produk } \\
\hline & Kopi reguler dan kopi luwak & $\begin{array}{l}\text { Green bean, roasted } \\
\text { bean }\end{array}$ & $\begin{array}{l}\text { Green bean } \\
\text { (washed process, } \\
\text { honey process, } \\
\text { natural Process, } \\
\text { semi-washed } \\
\text { process) } \\
\text { - Roasted } \\
\text { bean }\end{array}$ & $\begin{array}{l}\text { Green bean } \\
\text { (washed process, } \\
\text { honey process, } \\
\text { natural Process, semi-washed } \\
\text { process) } \\
\text { - } \quad \text { Roasted bean, } \\
\text { Ground coffee }\end{array}$ \\
\hline
\end{tabular}

Sumber : diadaptasi dari Lutfhi (2017) dan pengamatan lapangan

Tofografi dan agroklimat wilayah Pangalengan berada di pegunungan atau daerah perbukitan dengan ketinggian tempat 984 - $1.571 \mathrm{mdpl}$ dan memiliki suhu rata-rata harian $16^{\circ}-25^{\circ} \mathrm{C}$ dan 2015 curah 1.996 $\mathrm{mm} /$ tahun (BPS, 2017). Kondisi wilayah ini cocok untuk tanaman kopi. Daerah

Pangalengan memiliki 3 kawasan pegunungan potensial yang terindikasi geografis sebagai penghasil kopi Arabika java preanger yaitu Gunung Patuha, Gunung Malabar dan gunung Tilu. Berdasarkan hasil uji citarasa dari Puslitkoka tahun 2006 produk kopi yang dihasilkan oleh ketiga gunung tersebut memiliki nilai masing- masing $82,75,82,75$ dan 84,08 . Kondisi agroklimat desa
Margamulya yang merupakan daerah pegunungan dengan ketinggian kurang lebih 1500 meter dpl memiliki kelembaban udara sekitar $60,7 \%$, beriklim tipe B dan memiliki suhu 15 s.d 35 C. Ph tanah desa Margamulya berkisar 4,8 s.d 5,6 sangat cocok untuk ditanami komoditas kopi.

Desa Pulosari merupakan cikal bakal pengembangan kopi di Pangalengan hingga akhirnya menyebar ke berbagai desa. Pada tahun 2016 tanama kopi sudah diusahakan di 8 desa yaitu Desa Pulosari, Margamulya, Margaluyu, Sukaluyu, Wanasari, Sukamanah, Tribaktimulya dan Lamajang.

Tabel 1.

Perkembangan Tanaman Kopi di Kecamatan Pangalengan 2008- 2016

\begin{tabular}{|l|l|l|l|l|l|}
\hline Tahun & \multicolumn{2}{|l|}{ Desa Margamulya } & \multicolumn{2}{|l|}{ Pangalengan } & $\begin{array}{l}\text { Harga jual } \\
\text { chery (Rp/kg) }\end{array}$ \\
\cline { 2 - 5 } & $\begin{array}{l}\text { Luas lahan } \\
\text { (Ha) }\end{array}$ & $\begin{array}{l}\text { Produksi } \\
\text { (ton) }\end{array}$ & $\begin{array}{l}\text { Luas lahan } \\
\text { (Ha) }\end{array}$ & $\begin{array}{l}\text { Produksi } \\
\text { (ton) }\end{array}$ & \\
\hline 2008 & 36,10 & 8,67 & 695.09 & 109,75 & 2500 \\
\hline 2011 & 225 & 669,0 & $1.324,95$ & $4.193,90$ & 5000 \\
\hline 2015 & 400 & 1200 & $1.312,20$ & $10.993,60$ & 6500 \\
\hline 2016 & 580 & 1740 & $1.208,10$ & $14.680,20$ & 7000 \\
\hline
\end{tabular}

Sumber : Perhutani BKPH Pangalengan (2008), KPKM, BPS (2017) 


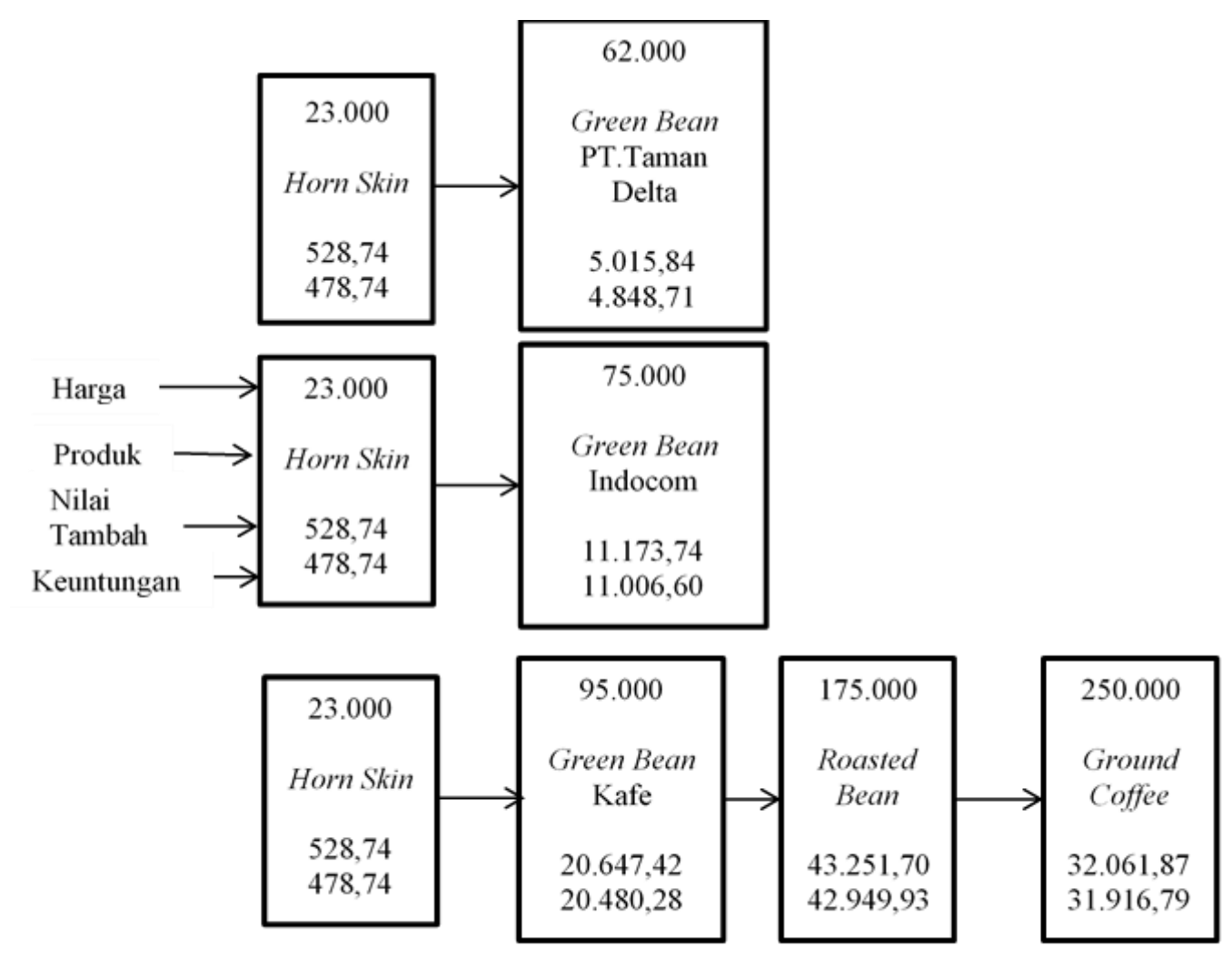

Gambar 4. Nilai Tambah dan Keuntungan Pengolahan Kopi di KPKM

Sumber : Tuti Karyani (2017)

Berdasarkan Tabel 3, luas perkebunan kopi di desa Margamulya meningkat dan di Kecamatan Pangalengan berpluktuasi namun produksi dan harga jualnya cenderung meningkat sepanjang tahun. Hal ini menandakan agroindustri kopi di kedua ewilayah ini berkembang dengan baik.

\section{Sebaran Nilai Tambah dan}

\section{Keuntungan Agroindustri Coffee Java}

Preanger Specialty. Agroindustri kopi yang dilakukan oleh Koperasi Produsen Kopi Margamulya(KPKM) menghasilkan beberapa varian produk diantaranya Hord skin (HS), green bean, roasted bean dan ground coffee dengan merek dagang Gunung Tilu.

Pengolahan Green bean memberikan nilai tambah berkisar Rp 5.015,84 s.d 20.647,42 per kilogram. Perbedaan nilai tambah ini disebabkan perbedaan nilai jual kepada konsumenya yaitu eksportir, distributor lokal atau cafe/kedai kopi. Green bean grade 1 dan
2 yang dijual ke eksportir PT Taman delta Indonesia dengan harga jual 62.000 per kilogram memberikan nilai tambah Rp $5.015,84$ per kilogram chery dan yang dijual ke cafe memberikan nilai tambah Rp 20.647,42per kilogram chery.

Sedangkan pengolahan roasted bean dan grounded coffee memberikan nilai tambah masing-masing 43.251,70 dan 32.051,78 per kilogram (Karyani, dkk, 2017). Dari data tersebut dapat dilihat bahwa nilai tambah terbesar diperoleh dari pengolahan chery menjadi gounded coffee. Namun volume poduksinya relatif sedikit hanya sekitar $5 \%$ untuk dijual langsung ke cafe atau konsumen akhir. Volume terbesar sekitar 80 $\%$ untuk pasar ekspor dijual dalam bentuk green bean.

Pengertian kopi luwak adalah kopi yang berasal dari buah kopi yang dimakan oleh luwak (Paradoxorus hermaphroditus) 
kemudian keluar bersama kotorannya berupa biji kopi dengan syarat biji kopi masih utuh terbungkus kulit tanduk dan dapat tumbuh jika ditanam kembali (Direktorat Jenderal Pengolahan dan Pemasaran Hasil Pertanian, 2015). Kopi luwak mulai dikembangkan sejak tahun 2000an oleh dua orang pengusaha kopi di Desa Margamulya yaitu bapak Dinuri Supriatna dan bapak Slamet Prayoga (PT sinar malyang lestari) dengan merek dagang kopi luwak golden Malabar. Harga Kopi Luwak berasan berkisar Rp. 800.000 per kilogram sedangkan dalam bentuk kopi bubuk berkisar Rp 1.000.000 s.d 1.200.000 per kilogram. Diversifikasi poduk kopi luwak dalam agroindustrialisasi kopi java prenger telah meningkatkan nilai tambah dan harga jual produk sehingga meningkatkan pendapatan pelaku agribisnis kopi.

\section{KESIMPULAN DAN SARAN}

Terjadi pertumbuhan pelaku pengolahan hasil pertanian, distribusi dan input pertanian kopi di desa Margamulya Pangalengan Bandung. Pada penyediaan bahan baku terjadi penambahan varietas bibit kopi yang baru yaitu nLine S 795 dan sigarar utang. Distribusi produk semakin bertambah dengan adanya kemitraan dengan eksportir, tumbuhkembangnya cafe/kedai kopi untuk pasar dalam negeri.

Perubahan kelembagaan dan keorganisasin melalui koordinasi vertikal. Pada aspek kelembagaan terbentuk masyarakat perlindungan indikasi geografis (MPIDG_KAJP). Koordinasi vertikal terjalin melalui kerjasama pelaku agroindustri dengan beberapa eksportir melalui sistem kontrak diantaranya PT Taman Delta, Indocom.

Terdapat perubahan dalam teknologi, komposisi produk dan perwilayahan. Adanya penambahana penggunaan teknologi mulai dari bibit kopi (on farm), panambahan alat dan teknik pengolahan kopi serta pengunaan teknologi informaatika dalam pemsaran produk agroinsustri kopi.

Terdapat nilai tambah dari agroindustri kopi arabika Java Preanger yang terdistribukan dalam bentuk keuntungan pengusaha agroindutri, pendapatan tenaga kerja dan penggunaan input lainnya.

\section{DAFTAR PUSTAKA}

Anonim. 2017. Kecamatan Pangalengan Dalam Angka Tahun 2016. Biro Pusat Statistik Kabupaten bandung

Anonim. 2017. Statistik perkebunan Indonesia 2015-2017. Kopi. Direktorat jenderal Perkebunan. Sekretariat Direktorat Jenderal Perkebunan Kementerian Pertanian, Jakarta http://ditjenbun.pertanian.go.id/tinymcp uk/gambar/file/statistik/2017/Kopi2015-2017.pdf.

Creswell, John W. 2010. Research Design Pendekatan Kualitatif, Kuantitatif, dan Mixed. Yogyakarta: Pustaka Pelajar.

Karyani Tuti, Djuwendah E dan Hermita Sadeli. 2017. Pembiayaan Rantai Nilai dan Agroindusrtialisasi Kopi Java Preanger Berorientasi Pasar Tersktuktur. Laporan Riset Kompetensi Dosen Unpad. Fakulatas Pertanian Unpad

Lufthi, Ahmad 2017. Proses Kebangkitan Kopi Arabica Java Preanger di Kecamatan Pangalengan. Skripsi pada Prodi agribisnis, UNPAD, Bandung

Mayasari, Devi. 2016. Agroindustrialisasi Ubi Cilembu di Kabupaten Sumedang. Skripsi Prodi Agribisnis, Faperta Unpad

Noor. Trisna Insan. 2011. Pengaruh Agroindustri Perberasan terhadap

Pembangunan Pertanian Berdasarkan Agroekosistem Lahan Sawah Irigasi di Jawa Barat. disertasi Program pasca sarjana UNPAD

Palupi, Retno. 2014. Keragaan Beberapa Varietas Kopi Arabika pada Areal Pengelolaan Hutan Bersama Masyarakat (PHBM). Jurnal Warta Vol. 26 No 1. Februari 2014. ISSN 0215-1308, penerbit Penerbit: Pusat Penelitian Kopi dan Kakao Indonesia.

Kirana Sesilia dan Tuti Karyani. Nilai tambah rantai pasok kopi pada koperasi produsen kopi margamulya di kecamatan pengalengan kabupaten bandung: Agrisep Vol 16 no. 2 september 2017 hal: 165 - 176, issn: 1412-8837 e-issn: 2579-9959

Widowati, Eny Hari, 2013. Faktor yang Menentukan Pengembangan Agroindustri Kopi Olahan di Kabupaten Temanggung, Seminar Nasional: mengagas kebangkitan 
komoditas Unggulanm Lokal Pertanian dan klautan, Fakultas Pertanian

Universitas Trunojoyo Madura.

https://anzdoc.com/seminar-nasional-

menggagas-kebangkitan-komoditas-

unggulan-

loec4a2dab15bb3cf7119501f2d2bf3e25

69128.html

Wisiana, Murdiyah, W dan Tarunasesna.

2015. Perkembangan Pertanian Kopi

Rakyat di Desa Margamulya

Kecamatan Pangelenan Tahun 1990-

2015 dari Tradisional ke Sistem

Agribisnis.

Xena Ghea Levina dan Lucyana Trimo.

2014. Potensi Pengembangan

Agroindutri Java Preanger coffee.

Proseding semninar nasional

Pembangunan Inklusif di Sektor

Pertanian, November 2014,

Departemen sosial Ekonomi Fakultas

Pertanian Unpad. 
Vol. 3, No. 1, Juli 2018: 359-426

AGRICORE:Jurnal Agribisnis dan Sosial Ekonomi Pertanian 